\title{
Hemoporfin-mediated photodynamic therapy for the treatment of port-wine stain birthmarks in pediatric patients ${ }^{*}$
}

\author{
Yunjie Zhang ${ }^{1}$ \\ Hongxia Chen ${ }^{1}$
}

\author{
Shuang Jiang ${ }^{2}$ \\ Xianbiao $\mathrm{Zou}^{1}$
}

DOI: http:/ /dx.doi.org/10.1590/abd1806-4841.20176431

\begin{abstract}
Port-wine stain is a type of common congenital superficial telangiectasia in the dermal layer mostly occurring on the forehead, face, and neck. The affected skin shows abnormal red or purple lesions, which darken and thicken. Nodular changes may develop with advancing age. If untreated, port-wine stains scarcely regress, which can have serious lifelong psychological impact on patients and affect their quality of life. In this report, we focused on two cases of port-wine stain in pediatric patients; the youngest patient was only 1.5 years old. During and after treatment, Hemoporfin-mediated photodynamic therapy features fewer adverse reactions, short light protection period, easy nursing, and good efficacy.
\end{abstract}

Keywords: Case reports; Pediatrics; Photochemotherapy

\section{INTRODUCTION}

Port-wine stain (PWS), which is also known as nevus flammeus or nevus telangiectaticus, is a type of common congenital telangiectasia in the dermal layer, with an incidence of 3-5 cases per 1,000 newborn babies. PWS often occurs unilaterally on the face, neck, and scalp at birth or shortly after birth. It can enlarge with the growth of the human body and scarcely regresses without intervention. ${ }^{1-2}$ According to color and dermal hyperplasia, PWS can be classified into pink type, purple type, and nodular thickening type. ${ }^{3}$ We report two cases of pink PWS in pediatric patients cured by Hemoporfin-mediated photodynamic therapy (PDT).

\section{CASE REPORT}

Case 1: A 1.5-year-old male patient had a pink skin lesion on the right cheek that would completely fade if the skin were pressed (Figure 1). Case 2: A 3-year-old female patient had a pink skin lesion on the right cheek that would completely fade if the skin were pressed (Figure 2). Therapy: we adopted Hemoporfin as photosensitizer (manufactured by Shanghai Fudan-zhangjiang Bio-Pharmaceutical Co., Ltd., GYZZ H20120076). The patients were required to take a routine skin test for the photosensitizer since only patients with a negative skin test result can receive the treatment. Before the treatment, the patients' unaffected skin around the lesion was

Received on 29.08.2016

Approved by the Advisory Board and accepted for publication on 09.01.2017

* Work performed at the First Affiliated Hospital of PLA General Hospital - Beijing, China.

Financial support: Clinical Scientific Research Supporting Fund of Chinese PLA General Hospital : 2015FC-TSYS-3045, 2014FC-TSYS-1014

Conflict of interest: None.

Department of Dermatology at the First Affiliated Hospital of PLA General Hospital - Beijing, China.

Department of Hematology at the First Affiliated Hospital of PLA General Hospital - Beijing, China.

@ 2017 by Anais Brasileiros de Dermatologia 

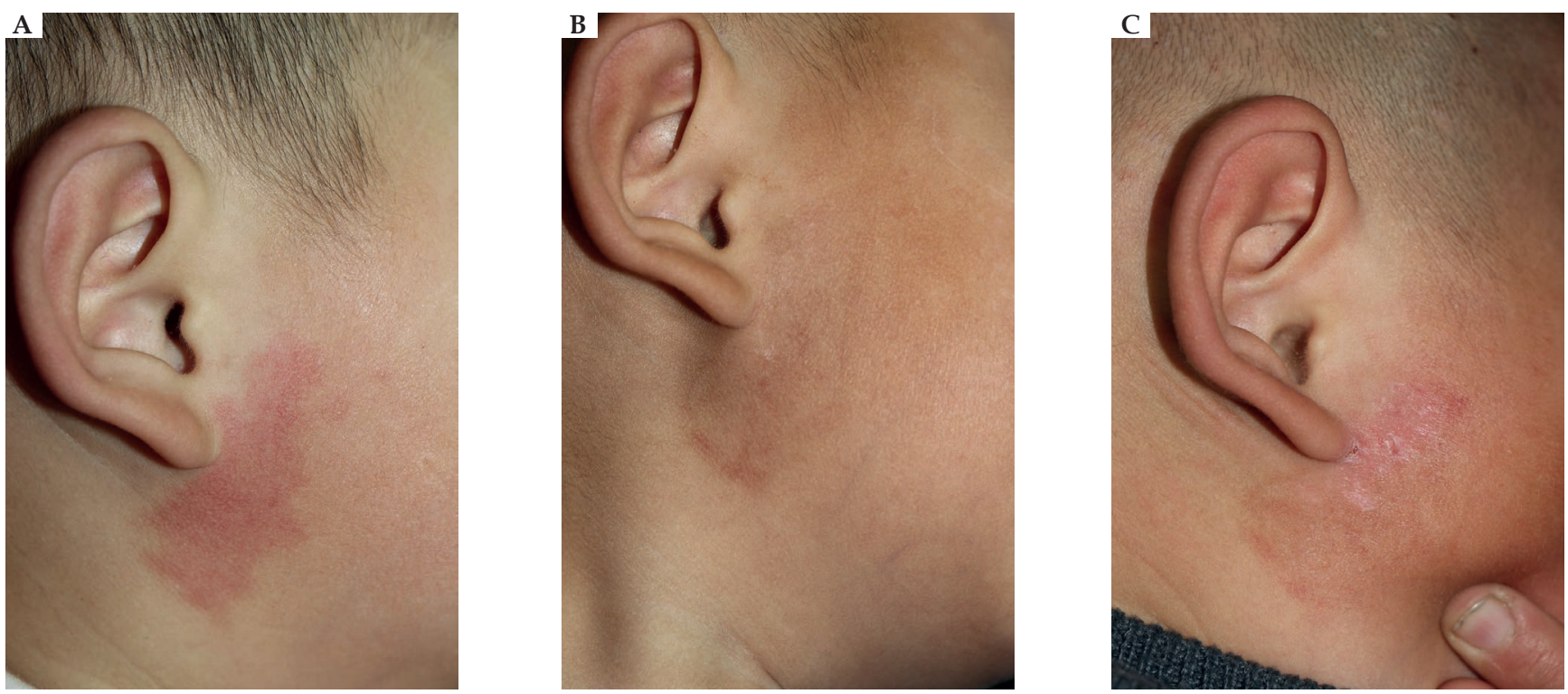

Figure 1: A - 1.5-year-old boy before PDT treatment; B - Patient after two PDT sessions; C - Scabbed lesion
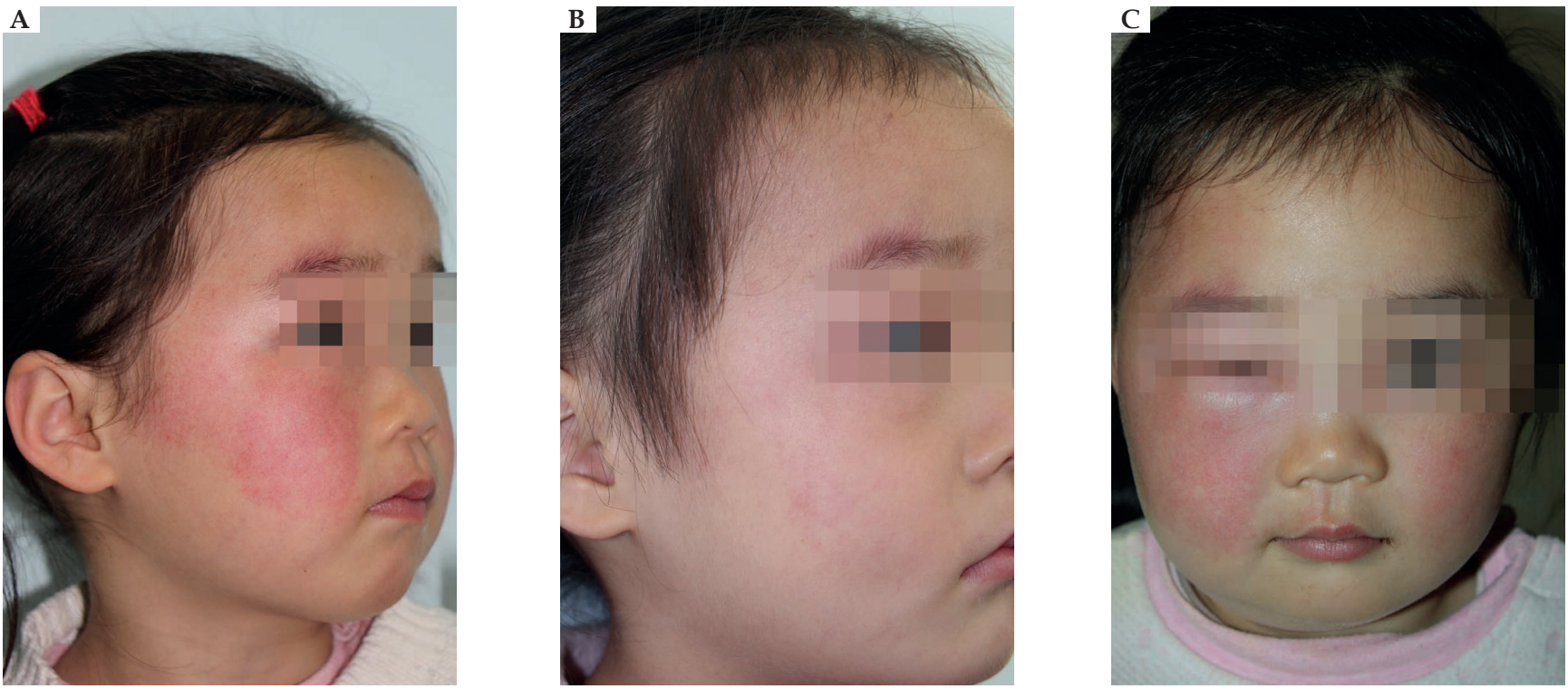

Figure 2: A - 3-year-old girl before PDT treatment; B - Patient after three PDT sessions; C - Swollen lesion

covered with a red and black double-sided shade cloth. Afterwards, we injected the IV photosensitizer (Hemoporfin) at a dose of $5 \mathrm{mg} /$ $\mathrm{kg}$. The laser device was a 535-nm LED green-light therapeutic apparatus (manufactured by Wuhan Yage). Treatment time was set at 20 minutes per light spot. Treatment details are shown in table 1. Result: after 2-3 treatment sessions with PDT, PWS on the patients' face were completely removed. (Figures 1 and 2)

\section{DISCUSSION}

Photodynamic therapy (PDT) was originally used as a clinical therapy for malignant tumors. In China, it was approved to be applied in the treatment of condyloma acuminatum and later adopted to treat diseases such as acne, laryngeal papilloma, nasal inverted papilloma, and solar keratosis. ${ }^{4-6}$ In 1991, Gu Ying et al. reported the application of PDT in the treatment of PWS for the first time, achieving a satisfactory result. ${ }^{7}$ According to the principle of PDT for PWS, the photosensitizer can reach peak concentration in the blood immediately after being intravenously injected and can be quickly absorbed by vascular endothelial cells. Then, a specific wavelength of laser is used to irradiate and destroy deformed capillary networks that contain the photosensitizer at an appropriate dosage, but the laser cannot damage sub-dermal extracellular matrixes and normal epidermal cells that do not contain or contain few photosensitizers. In other words, PDT can achieve the therapeutic effect by effectively destroying deformed capillary networks while preserving normal tissue on the surface and around lesions. ${ }^{8}$ In this 


\begin{tabular}{|c|c|c|c|c|c|c|c|c|c|}
\hline No. & Gender & Age & $\begin{array}{l}\text { Location of } \\
\text { the lesion }\end{array}$ & Drug dose & $\begin{array}{l}\text { PDT } \\
\text { sessions }\end{array}$ & Light dose & $\begin{array}{l}\text { Treatment } \\
\text { time }\end{array}$ & $\begin{array}{l}\text { General } \\
\text { anesthesia }\end{array}$ & $\begin{array}{l}\text { Light } \\
\text { protection } \\
\text { period }\end{array}$ \\
\hline 1 & Male & 1.5 years old & Right cheek & $5 \mathrm{mg} / \mathrm{kg}$ & 2 & $95 \mathrm{mw} / \mathrm{cm}^{2}$ & 25 minutes & Yes & 2 weeks \\
\hline 2 & Female & 3 years old & Right cheek & $5 \mathrm{mg} / \mathrm{kg}$ & 3 & $95 \mathrm{mw} / \mathrm{cm}^{2}$ & 25 minutes & Yes & 2 weeks \\
\hline
\end{tabular}

report, we used PDT to treat two cases of pink PWS in pediatric patients with good efficacy in both cases. After treatment, the lesions became red and swollen, which receded around one week later (Figure 2). One patient's lesion scabbed over, which did not scar after falling off (Figure 1). Both of the patients were protected from light for two weeks after treatment with no allergic reaction during and after the light protection period. Compared with previous reports about PDT for PWS in pediatric patients (in which the youngest age was three years old), this report is unique in that it brings one case aged at 1.5 years old with significant efficacy and no adverse event after treatment. ${ }^{8,9}$ After a 2-year follow-up, we observed no relapse. In conclusion, Hemoporfin-mediated PDT shows fewer adverse reactions, high safety, short light protection period, easy nursing, and definite efficacy for the treatment of pink PWS.

\section{REFERENCES}

1. Rajaratnam R Laughlin SA, Dudley D. Pulsed dye laser double-pass treatment of patients with resistant capillary malformations. Lasers Med Sci. 2011;26:487-92.

2. Chen JK, Ghasri P, Aguilar G, van Drooge AM, Wolkerstorfer A, Kelly KM, et al. An overview of clinical and experimental treatment modalities for port wine stain. J Am Acad Dermatol. 2012;67:289-304.

3. Gu Y, Li JH, Jiang YP. Preliminary clinical observation of HMME in PDT for PWS. Clin J laser Med Surg. 1996;5:201-204.

4. Zhang Y, Yang Y, Zou X.. Efficacy of 5-aminolevulinic acid photodynamic therapy for treatment of nasal inverted papilloma, Photodiagnosis Photodyn Ther. 2013:10:549-51.

5. Zhang Y, Yang Y, Zou X, Huang Z. 5-Aminolevulinic Acid Photodynamic Therapy combined with C02 Laser Therapy in treatment of laryngeal papilloma: Case report. Photodiagnosis Photodyn Ther. 2016 Jun;14:131-3.

6. Yang YG, Zou XB, Zhao H, Zhang YJ, Li HJ. Photodynamic Therapy of Condyloma Acuminata in Pregnant Women Chin Med J (Engl). 2012;125:2925-8.

7. Gu Y, Li JH, Jiang YP. A clinical study of photodynamic therapy for port wine stain: a report of 40 cases. Clin J laser Med Surg. 1992;1:6-10.

8. Zhang B, Zhang TH, Huang Z, Li Q, Yuan KH, Hu ZQ. Comparison of pulsed dye laser (PDL) and photodynamic therapy (PDT) for treatment of facial port-wine stain (PWS) birthmarks in pediatric patients. Photodiagnosis Photodyn Ther. 2014;11:491-7.

9. Zhao Y, Zhou Z, Zhou G, Tu P, Zheng Q, Tao J, et al. Efficacy and safety of hemoporfin in photodynamic therapy for port-wine stain: a multicenter and openlabeled phase lla study. Photodermatol Photoimmunol Photomed. 2011;27:17-23.

\author{
MAILING ADDRESS: \\ Xianbiao Zou \\ NO.51 Fu Cheng Road \\ Beijing, China. \\ E-mail:zouxianbiao25@sina.com
}

How to cite this article: Zhang Y, Jiang S, Chen H, Zou X. Hemoporfin-mediated photodynamic therapy for the treatment of port-wine stain birthmarks in pediatric patients. An Bras Dermatol. 2017;92(4):559-61. 